\title{
AUTONOMOUS \& CONTROLLED MOTIVATION AND ACADEMIC OUTCOMES AMONG UNIVERSITY STUDENTS
}

\author{
Maryum Firdous \\ Lecturer, \\ Department of Psychology, Mohammad Ali Jinnah University, \\ Sindh, Pakistan \\ Email: maryum.firdous@jinnah.edu
}

\section{Rabia Riaz}

Assistant Professor,

Department of Psychology, University of Karachi,

Sindh, Pakistan

Email: rabia.riaz@uok.edu.pk

\begin{abstract}
Motivation has immense significance in human functioning. Self-determination theory describes motivation as autonomous and controlled types. The objective of this study was to explore the association between university students' autonomous and controlled motivation and their two important academic outcomes: critical thinking skills and academic performance. The study sample consisted of 193 participants (57 men and 136 women) studying at the University of Karachi, Pakistan. Participants' autonomous and controlled motivation was assessed by the modified Academic Motivation Scale, critical thinking was assessed by the Critical Thinking scale of the Motivated Strategies for Learning Questionnaire, and academic performance was measured by the Subjective Academic Performance Scale. The analysis showed a significant medium-level positive association between students' autonomous motivation and their critical thinking skills, and weak significant positive association between controlled motivation and their critical thinking skills and academic performance. However, autonomous motivation was not significantly associated with academic performance. It was also determined that differences in autonomous and controlled motivation scores of students with reference to their year of study were not significant. The findings highlight that both autonomous and controlled motivation may have a positive role in academic outcomes at university level in collectivist contexts.
\end{abstract}

\section{KEYWORDS}

Autonomous motivation, controlled motivation, critical thinking skills, academic 
performance, self-determination theory

\section{INTRODUCTION}

Motivation is the reason why a person behaves in a certain way. It is the reason behind any action or goal. For example, the reason behind studying hard and trying to achieve good grades may be the family pressure or the desire for a good job in future. As noted by Buzdar, Mohsin, Akbar, and Mohammad (2017), student motivation is very important as it affects them in many ways including their learning and academic outcomes, such as performance, academic skills, retention, self-efficacy and institutional satisfaction.

Self-determination theory proposes that autonomous motivation ensures an experience of willingness and choice. It relates to the gratification of the three basic psychological needs: relatedness, competence and autonomy. Hence, it is good quality motivation and desired for optimal human functioning (Claver Martínez-Aranda, Conejero, \& Gil-Arias, 2020). On the other hand, controlled motivation gives the feelings of pressure and causes the frustration of the human needs. Hence it is considered bad quality motivation and detrimental to human functioning (Tsoi et al., 2018).

The aforementioned propositions of the Self-determination theory have been empirically tested in different contexts. The findings of these studies show that autonomous motivation is correlated positively to wellbeing and academic variables. However, findings on controlled motivation are inconsistent. In developing countries, such as the Philippines and Thailand, high controlled motivation was correlated to high wellbeing and academic performance (d'Ailly, 2003). Therefore, it becomes necessary to establish sound evidence on the role of controlled motivation in developing countries. Further, since students' motivation may impact their goals of learning and achievement, it is crucial to understand their motivation in different years of university education. By this understanding, educators would be able to work productively on student motivation and take meaningful steps for student academic success at university level. Therefore, this study explored the association of students' critical thinking and academic performance with their autonomous and controlled motivation, in a Pakistani context. Also, this study has investigated the differences in motivation in the four years of university.

\section{LITERATURE REVIEW}

\section{Autonomous and Controlled Motivation}

According to the Self-determination theory, autonomous motivation is good quality motivation. Autonomous motivation comprises of intrinsic regulation and identified regulation (Deci \& Ryan, 2008). Intrinsic regulation is generated internally, such as personal interest. If a person studies a particular subject to draw pleasure and 
satisfaction, this regulation is called intrinsic. Identified regulation means the person has identified with a particular goal and the goal has now become important for the person. For example, studying becomes important because of the chances of getting good job in future are associated with it. Controlled motivation, which is the other type, comprises of introjected regulation and external regulation (Deci \& Ryan, 2008). Introjected regulation means a person does something either to feel good or to avoid feeling bad. A good example is of the hardwork that is done to succeed to feel important. Finally, external regulation is the external purpose of a behavior, such as rewards and punishments.

The empirical research on motivation and academic outcomes suggests that good academic performance is associated with autonomous motivation (Claver et al., 2020). Further, autonomous motivation is found to be significantly positively correlated with concentration on studies (Vansteenkiste, Zhou, Lens, \& Soenens, 2005), academic planning (Brunet, Gunnell, Gaudreau, \& Sabiston, 2015), persistence (Brunet, Burke, \& Sabiston, 2013), and positive emotional experiences (Orsini, Binnie, \& Jerez, 2019). Landge, Sturges, Langdon, and Orvis (2019) investigated motivation and its relationship to study-time and perceived difficulty in the course among science students. They collected data at the start and end of two semesters. The analysis of this rich data demonstrated that autonomous motivation is related with increased studytime, as well as with high levels of perceived difficulty in the course. In the metaanalysis on motivation and academic outcomes, Howard, Bureau, Guay, Chong, and Ryan (2020) has found out that autonomous motivation is a positive factor for these outcomes.

For controlled motivation, studies have shown that it is associated with degree drop out and time-mismanagement (Vansteenkiste et al., 2005), burnout, fatigue and anxiety (Brunet et al., 2015), hesitation and effortless cognitive processing (Abassi \& Sh, 2014; Brunet et al., 2013), negative emotional experiences (Ketonen, Dietrich, Moeller, Salmela-Aro, \& Lonka, 2018) and lower energy (Tsoi et al., 2018). In a set of two researches, Bonneville-Roussy, Evans, Verner-Filion, Vallerand, and Bouffard (2017) explored how motivation is related to stress coping strategies among university students. They found that student's high controlled motivation was linked with their greater use of unhealthy stress coping strategies. However, in Taiwan, students' better academic performance was related with high controlled motivation (d'Ailly, 2003). In Pakistan also, greater academic success was related with intrinsic motivation and extrinsic motivation, which are the components of autonomous motivation and extrinsic motivation respectively (Brunet et al., 2015; Naz, Shah, \& Qayum, 2020). Here, extrinsic motivation caused 34 percent variance in performance and intrinsic motivation caused 23 percent variance in it (Afzal, Ali, Khan, \& Hamid, 2010). Since the findings on controlled motivation are inconsistent, such as in Pakistan and 
Thailand high controlled motivation was correlated to high academic performance, it is crucial to further explore student motivation and its role in academic outcomes. By this understanding, educators would be able to work productively on student motivation and take meaningful steps for student academic success at university level. Student motivation has also been observed to change in different years of university education. Sarkis et al (2020) demonstrated that students studying in second year of university had highest autonomous motivation of all, while students in the last year had the lowest scores of all. For controlled motivation, students of fourth year showed highest score, and students of first year had lowest score. These findings highlight that autonomous motivation declines and controlled motivation becomes more important as students progress in their university studies. These outcomes need to be explored further in different contexts.

\section{Critical Thinking}

Among the academic outcomes, critical thinking skill is an important outcome (York, Gibson, \& Rankin, 2015). Critical thinking skill is a cognitive skill that should be present in university degree holders (Dekker, 2020; Sutiani, Situmorang, \& Silalahi, 2021). Critical thinking skill enables a person to evaluate and analyze the information he receives (Ennis,2011). It positively relates to performance among all students, especially the university students (Marfu'i \& Sriyono, 2020; Ghanizadeh, 2017). Students, who lack this skill, use rote memorization as the primary tool of learning and thus readily forget as they learn. For long term learning and retention, this skill is necessary.

\section{Academic Performance}

Along with critical thinking skills, good academic performance is also of prime importance. It is an indicator of how much the student is successful in achieving the specified educational goals (Soufi, Damirchi, Sedghi, \& Sabayan, 2014). It is assessed in terms of students' results, their grades and GPA. Good academic performance is important as it encourages the students to retain and persist in studies. On the other hand, bad results and performance may result in demotivation and drop out (Buzdar et al., 2017). Higher grades and GPA are associated with autonomous motivation (Claver et al., 2020), while lower grades and GPA are associated with controlled motivation (Brunet et al., 2015; Manganelli et al., 2019).

\section{RESEARCH OBJECTIVES}

1. To find out the relationship between autonomous motivation and academic outcomes of university students.

2. To understand the relationship between controlled motivation and academic outcomes of university students.

3. To explore the difference in autonomous motivation among university students 
from different years of study.

4. To investigate the difference in controlled motivation among university students from different years of study.

\section{RESEARCH HYPOTHESES}

1. There will be no significant relationship between autonomous motivation and academic outcomes of university students

2. There will be no significant relationship between controlled motivation and academic outcomes of university students

3. There will be no significant difference in autonomous motivation among university students from different years of study

4. There will be no significant difference in controlled motivation among university students from different years of study

\section{RESEARCH METHODOLOGY \\ Participants}

The study sample was undergraduate students from University of Karachi. Participants were approached in the university premises and convenient sampling method was utilized. The sample consisted of 193 participants, in which 57 were men and 136 were women, aged between 18-31 years. Participants belonged to first through fourth year of study from the departments of sciences and social sciences.

\section{Data Collection Instruments}

\section{Demographic Form}

It consisted of questions for gender, age, current year of study, faculty and marital status.

\section{Academic Motivation Scale (AMS)}

Assessment of students' autonomous and controlled motivation was done by the academic motivation scale. This scale was developed by Vallerand and his colleagues (1993). It was adapted to Pakistani education context with the authors' permission. The AMS consists of 28 items and assesses the reasons for going to university. A seven-point scale (1 indicates no correspondence and 7 indicates exact correspondence) is used to answer the items. The mean scores on intrinsic and identified regulation subscales are added to get the autonomous motivation score, and the mean scores on introjected and external regulation subscales are added to get the controlled motivation score. The subscales are internally consistent having cronbach's alpha 0.62-0.86. And the test-retest reliability is .79 (Vallerand et al., 1993).

\section{Critical Thinking Scale}

Motivated Strategies for Learning Questionnaire measures university students' motivation and learning strategies for a university course. It was developed by 
Pintrich, Smith, Garcia, \& McKeachie (1993). The 5-item critical thinking subscale is one of the learning strategies scales to assess critical thinking skills among students. Participants of the present study belonged to different courses and years of study, therefore, the scale was adapted to a general form, with the authors' permission. Items are scored on a seven-point scale, where 1 indicates no correspondence to 7 indicates high correspondence. Scoring is done by averaging the scores on the items. It has good predictive validity and an internal consistency of .80 (Duncan \& Mckeachie, 2015).

\section{Subjective Academic Performance Scale}

Subjective Academic Performance scale was developed by Leung and Xu (2013) and has one item: "My academic results are very good". An eleven points scale (0 indicates strong disagreement to 10 indicates strong agreement) is used to answer the item. Its content and construct validity are established (Leung \& Xu, 2013).

In this study, this measure was used instead of GPA and grades because the participants belonged to different departments and four undergraduate years. For this situation, it is preferable to measure performance by a scale that is not bound to subject and year of study (Etzel \& Nagy, 2015; Leung \& Xu, 2013). Also, grades of the firstyear students in the present study were not available because they had not yet appeared in a university exam.

\section{Procedure}

To conduct this study, permission was taken from the advanced studies and research board at the University of Karachi. 193 undergraduate students participated in the study through convenient sampling. Participants studying in the undergraduate programs in the first to fourth year of study in different faculties were approached in person in university premises. First, they were asked for written consent. Voluntary participation was ensured.

After providing consent, they filled the demographic form and scales, which included the Academic Motivation Scale (measures autonomous and controlled motivation), Critical Thinking Scale, and Subjective Academic Performance Scale. It took around 10 minutes. Confidentiality of the responses was ensured.

\section{Data Analysis}

Data was analyzed using SPSS (v. 22). Descriptive statistics (e.g., mean, standard deviation, minimum and maximum values) were calculated. Inferential statistical analysis included pearson moment correlation to find correlation between the study variables. ANOVA test was executed to find the difference in motivation of participants from the four years of university education. 


\section{RESULTS}

Descriptive Statistics

Table 1: Descriptive Statistics for Motivation and Academic Outcomes Scales

\begin{tabular}{lccccc}
\hline & Mean & $\begin{array}{c}\text { Std. } \\
\text { Deviation }\end{array}$ & Min & Max & N \\
\hline $\begin{array}{l}\text { Autonomous } \\
\text { Motivation }\end{array}$ & 10.56 & 1.87 & 4.75 & 14.00 & 193 \\
$\begin{array}{l}\text { Controlled } \\
\text { Motivation }\end{array}$ & 10.35 & 2.08 & 3.75 & 14.00 & 193 \\
$\begin{array}{l}\text { Critical } \\
\text { Thinking }\end{array}$ & 4.79 & 1.19 & 1.60 & 7.00 & 193 \\
$\begin{array}{l}\text { Academic } \\
\text { Performance }\end{array}$ & 6.60 & 2.16 & 0.00 & 10.00 & 193 \\
\hline
\end{tabular}

Table 1 presents the descriptive values of autonomous and controlled motivation, critical thinking and academic performance.

Table 2: Correlation between Autonomous Motivation and Academic Outcomes

\begin{tabular}{lllll}
\hline & & $\begin{array}{l}\text { Autonomous } \\
\text { Motivation }\end{array}$ & $\begin{array}{l}\text { Critical } \\
\text { Thinking }\end{array}$ & $\begin{array}{l}\text { Academic } \\
\text { Performance }\end{array}$ \\
\hline Autonomous & Pearson & 1 & $.348^{* *}$ & .044 \\
Motivation & Correlation & & .000 & .540 \\
& Sig. (2-tailed) & & 193 & 193 \\
& N & 193 & 1 & $.365^{* *}$ \\
Critical & Pearson & $.348^{* *}$ & & .000 \\
Thinking & Correlation & .000 & & 193 \\
& Sig. (2-tailed) & .000 & 193 & 1 \\
Academic & N & 193 & $.365^{* *}$ & 1 \\
Performance & Corron & .044 & .000 & \\
& Sig. (2-tailed) & .540 & 193 & 193 \\
& N & 193 & & \\
\hline
\end{tabular}

Table 2 shows the correlation of autonomous motivation with critical thinking and academic performance. The correlation between autonomous motivation and critical thinking was medium and significantly positive $\left(r=.348^{* *}, p=.000\right)$. However, autonomous motivation was not significantly related to academic performance. 


\begin{tabular}{lllll}
\hline \multicolumn{4}{l}{ Table 3: Correlation between Controlled Motivation and Academic Outcomes } \\
\hline & & $\begin{array}{l}\text { Controlled } \\
\text { Motivation }\end{array}$ & $\begin{array}{l}\text { Critical } \\
\text { Thinking }\end{array}$ & $\begin{array}{l}\text { Academic } \\
\text { Performance }\end{array}$ \\
\hline Control Pearson Correlation & 1 & $.208^{* *}$ & $.151^{*}$ \\
led Sig. (2-tailed) & & .004 & .036 \\
Motiva N & & 193 & 193 & 193 \\
tion & & & 1 & $.365^{* *}$ \\
Critical & Pearson Correlation & $.208^{* *}$ & & .000 \\
Thinking & Sig. (2-tailed) & .004 & 193 & 193 \\
& $\mathrm{~N}$ & 193 & $.365^{* *}$ & 1 \\
Academic & Pearson Correlation & $.151^{*}$ & .000 & \\
Performance & Sig. (2-tailed) & .036 & 193 & 193 \\
& $\mathrm{~N}$ & 193 & & \\
\hline
\end{tabular}

Table 3 shows that the correlation between controlled motivation and critical thinking ( $\left.r=.208^{* *}, p=.004\right)$, and between controlled motivation and academic performance $\left(r=.151^{*}, p=.036\right)$ were significantly positive, although the relationships were weak.

Table 4: Descriptive of Autonomous Motivation by Year of Study

\begin{tabular}{lcccccc}
\hline & & \multicolumn{5}{c}{ Std. } \\
& & Mean & Deviation Minimum & Maximum \\
\hline Autonomous & $1^{\text {st }}$ Year & 47 & 10.606 & 1.731 & 7.250 & 13.500 \\
Motivation & $2^{\text {nd }}$ Year & 56 & 10.710 & 1.978 & 6.500 & 14.000 \\
& $3^{\text {rd }}$ Year & 44 & 10.176 & 2.153 & 4.750 & 13.500 \\
& $4^{\text {th }}$ Year & 46 & 10.717 & 1.580 & 7.500 & 13.750 \\
\hline
\end{tabular}

Table 4 describes that the mean scores for autonomous motivation for all study years were more than 10. Small standard deviation scores that are in the range of 1.5802.153 show participants' consistency in responses. Minimum and maximum scores show the data range.

Table 5: Difference between Autonomous Motivation with reference to Year of University

\begin{tabular}{ccccccc}
\hline & & Sum of & & Mean & & \\
Squares & df & Square & F & Sig. \\
\hline Autonomous & Between Groups & 8.977 & 3 & 2.992 & .851 & .468 \\
Motivation & Within Groups & 664.589 & 189 & 3.516 & & \\
& Total & 673.565 & 192 & & & \\
\hline
\end{tabular}


Table 5 shows the results of one-way ANOVA test. There was no significant difference in autonomous motivation among the students of the four years $(\mathrm{F}=.851$, $\mathrm{p}=.468$ ). Therefore, the alternative hypotheses have been rejected in favour of null hypotheses. Year of study did not impact participants' autonomous motivation.

Table 6: Descriptive of Controlled motivation by Year of Study

\begin{tabular}{lllllll}
\hline & & & & Std. \\
Deviation & Minimum & Maximum \\
\hline Controlled & $1^{\text {st }}$ Year & 47 & 10.473 & 2.030 & 6.250 & 13.750 \\
Motivation & $2^{\text {nd }}$ Year & 56 & 10.670 & 2.178 & 3.750 & 14.000 \\
& $3^{\text {rd }}$ Year & 44 & 9.852 & 1.917 & 6.000 & 13.750 \\
& $4^{\text {th }}$ Year & 46 & 10.326 & 2.150 & 5.750 & 13.750 \\
\hline
\end{tabular}

Table 6 describes that the mean scores for controlled motivation for all study years were more than 10 . Only in the third year the mean score of controlled motivation was 9.852. Small standard deviation scores that are in the range of 1.917-2.178 show participants' consistency in responses. Minimum and maximum scores show the data range.

Table 7: Difference between Controlled Motivation with reference to Year of University

\begin{tabular}{lcccccc}
\hline & & Sum of & Mean & & \\
& & Squares & df & Square & F & Sig. \\
\hline Controlled & Between Groups & 17.361 & 3 & 5.787 & 1.340 & .263 \\
Motivation & Within Groups & 816.441 & 189 & 4.320 & & \\
& Total & 833.802 & 192 & & & \\
\hline
\end{tabular}

Table 7 shows the results of one-way ANOVA test. The difference in participants' controlled motivation was insignificant $(\mathrm{F}=1.340, \mathrm{p}=.263)$. Therefore, the alternative hypotheses have been rejected in favour of null hypotheses. Year of study did not impact participants' controlled motivation.

\section{DISCUSSION}

Motivation plays an important role in students' lives. Students may study because of several reasons, including their own interest in learning and societal pressures. The Self-determination theory has described motivation as being autonomous and controlled (Ryan \& Deci, 2017). Autonomous and controlled motivation is assumed to respectively have a positive and negative role in human functioning (Deci \& Ryan, 2008). 
In the present study, the association of university students' autonomous and controlled motivation with two important academic outcomes, critical thinking skills and academic performance, was assessed. Differences in autonomous and controlled motivation with reference to the year of study were also calculated. For the first research question, it was found that autonomous motivation and critical thinking skills had a significant positive correlation but autonomous motivation and academic performance were not significantly correlated (Table 2).

The positive relationship between autonomous motivation and critical thinking skills that we have found was expected. Researchers have found that autonomous motivation is linked to good academic skills including study-effort (Kusurkar, Cate, Vos, Westers, \& Croiset, 2013) and use of effective strategies of learning (Orsini et al., 2019). High autonomous motivation is also linked to increased engagement in study (King \& Datu, 2017). However, we surprisingly found that academic performance of our participants was not significantly linked to their autonomous motivation. It may be because of the reason that some factors are necessary for student performance, and autonomous motivation alone may not work out to enhance students' performance. These factors involve personal characteristics such as academic self-efficacy, self-concept, emotional intelligence, and personality traits; time management skills; educational experiences like internships and teacher-support; and demographic factors such as socio-economic background (Smith \& White, 2015). Besides, autonomous motivation may lead students to focus on acquiring skills and growth. This focus may lower the competition among students and the desire to perform better than their fellows. Ranellucci, Hall, Muis, Lajoie, \& Robinson (2017) have pointed out that when students aim at gaining in-depth understanding of the content, their concern for high academic results becomes notably less.

In our study, controlled motivation also had a significant positive correlation with critical thinking and academic performance (Table 3). Hence, the findings exhibited that not only students' high autonomous motivation is linked with their higher critical thinking skills, but their high controlled motivation is also associated with their higher critical thinking skills and academic performance. The positive associations between controlled motivation and academic outcomes found in the present study were not surprising. King and Datu (2017) has stated that controlled motivation may not be a cause of malfunctioning in collectivist contexts like our Pakistani society. This can be because the aspirations of others, including parents, family members, and teachers, are important for students. Also, personal choice is less important for them (Triandis, 2018). Therefore, they may perceive autonomous and controlled motivation as similar and not distinct types of motivation (Tsoi et al., 2018). Further, both autonomous and controlled motivation may be a source of the basic needs' gratification in these contexts. In Chile, which is a developing and collectivistic country similar to Pakistan, 
Orsini, Binnie, Wilson, \& Villegas (2018) studied motivation and needs for freedom, competence, and connectedness of dental students. Their results demonstrated that both autonomous and controlled motivation of students was positively linked to their basic need satisfaction.

The findings of the present study provide support to those found in other collectivist and developing societies. For instance, the study conducted in the Philippines indicated that participants' high controlled motivation was linked to their academic performance and buoyancy (Datu \& Yang, 2019). Another study conducted in Taiwan highlighted that high controlled motivation was associated with students' academic performance (d'Ailly, 2003). Another study conducted in Poland showed that high controlled motivation was related to the students' learning goals (Siwek, Oleszkowicz, \& Stowinska 2017). Further, studies in China demonstrated that controlled motivation was not harmful to participants' results, their focus on studies, study planning and energy (Vansteenkiste et al, 2005). Similarly, it was not detrimental to student engagement and achievement in the Philippines (King \& Datu, 2017).

It was also found in the present study that mean autonomous and controlled motivation scores of students from all four years were high and were not significantly different in the four years of university (Table 5 and 7). Our result may have a number of reasons. At university level, usually students choose interest-based subjects (Wormington, Corpus, \& Anderson, 2012) and because of this, their autonomous motivation reamins high throughout the years. To complete their degree, students also need to study and persist in the courses that are not of their interest (Van Soom \& Donche, 2014). Therefore, they experience controlled motivation too (Guay, Roy \& Valois, 2017). Our result is opposite to that of the recent study (Sarkis et al., 2010), where autonomous motivation was greater in the second year of study and controlled motivation was greater in the fourth year of study. This is perhaps because their participants were medical students and medical study is different from that of nonmedical students. Motivation level may change throughout university years among medical students but not in non-medical students.

The sample in the present study was recruited from one public sector university of Pakistan. Therefore, the interpretation of results requires a consideration of the specific context where the study was conducted. Also, we did not investigate whether our sample's controlled motivation was actually satisfying their basic psychological needs. It is a possibility that participants' high scores on controlled motivation and academic outcome measures explained the positive correlation between controlled motivation and academic outcomes.

The present study explored the relationship between autonomous and controlled 
motivation and two important academic outcomes (critical thinking skills and academic performance) of university students. Autonomous motivation had a significant positive correlation with critical thinking skills. Also, controlled motivation had a significant positive correlation with critical thinking skills and academic performance. No significant relationship between autonomous motivation and academic performance was found. Also there were no significant differences in autonomous and controlled motivation scores of students with reference to their year of study.

\section{RECOMMENDATIONS}

Given the results of the present study, it is suggested that not only autonomous motivation but controlled motivation can also play a positive role in students' academic outcomes. Therefore, educators need to consider the designing of certain interventions which can help increase student motivation. Future researchers should also verify the results of this study in different government and private universities and in other developing and collectivist contexts for an in-depth understanding of motivation in these contexts. A longitudinal design may also be employed to enhance the knowledge of how motivation impacts academic outcomes over the academic years from school through university. Finally, researchers should also explore the role of controlled motivation in need satisfaction in developing contexts.

\section{REFERENCES}

Abassi, M., \& Sh, D. (2014). Role of Procrastination, Self-Regulation and Metacognition in Predicting Students' Academic Motivation. Education Strategies in Medical Sciences, 7(5), 273-278.

Afzal, H., Ali, I., Khan, M. A., \& Hamid, K. (2010). A study of university students' motivation and its relationship with their academic performance. Available at SSRN 2899435.

Bonneville-Roussy, A., Evans, P., Verner-Filion, J., Vallerand, R. J., \& Bouffard, T. (2017). Motivation and coping with the stress of assessment: Gender differences in outcomes for university students. Contemporary educational psychology, 48 , $28-42$.

Brunet, J., Burke, S. M., \& Sabiston, C. M. (2013). The benefits of being self-determined in promoting physical activity and affective well-being among women recently treated for breast cancer. Psycho-Oncology, 22(10), 2245-2252.

Brunet, J., Gunnell, K. E., Gaudreau, P. \& Sabiston, C. M. (2015).An integrative analytical framework for understanding the effects of autonomous and controlled motivation. Personality and Individual Differences, 84, 2-15.

Buzdar, M. A., Mohsin, M. N., Akbar, R., \& Mohammad, N. (2017). Students' Academic Performance and its Relationship with their Intrinsic and Extrinsic Motivation. Journal of Educational Research, 20(1), 74. 
Claver, F., Martínez-Aranda, L. M., Conejero, M., \& Gil-Arias, A. (2020). Motivation, Discipline, and Academic Performance in Physical Education: A Holistic Approach from Achievement Goal and Self-Determination Theories. Frontiers in Psychology, 11, 1808.

d'Ailly, H. (2003). Children's autonomy and perceived control in learning: A model of motivation and achievement in Taiwan. Journal of Educational Psychology, 95, 84-96.

Datu, J. A. D., \& Yang, W. (2019). Academic buoyancy, academic motivation, and academic achievement among filipino high school students. Current Psychology, 1-8.

Deci, E. L., \& Ryan, R. M. (2008). Facilitating optimal motivation and psychological wellbeing across life's domains. Canadian psychology/ Psychologie canadienne, 49(1), 14.

Dekker, T. J. (2020). Teaching critical thinking through engagement with multiplicity. Thinking Skills and Creativity, 37, 100701.

Duncan, T., \& Mckeachie, W. J. (2015). Motivated Strategies for Learning Questionnaire (MSLQ) Manual. DOI:10.13140/RG.2.1.2547.6968. ResearchGate.

Ennis, R. (2011). Critical thinking. Inquiry: Critical Thinking Across the Disciplines, 26(1), 4-18.

Etzel, J. M., \& Nagy, G. (2015). Students' Perceptions of Person-Environment Fit Do Fit Perceptions Predict Academic Success Beyond Personality Traits? Journal of Career Assessment, 1069072715580325.

Ghanizadeh, A. (2017). The Interplay between Reflective Thinking, Critical Thinking, SelfMonitoring, and Academic Achievement in Higher Education. Higher Education, 74(1), 101-114.

Guay, F., Roy, A., \& Valois, P. (2017). Teacher structure as a predictor of students' perceived competence and autonomous motivation: the moderating role of differentiated instruction. British Journal of Educational Psychology, 87(2), 224-240.

Howard, J., Bureau, J., Guay, F., Chong, J., \& Ryan, R. M. (2020). Student motivation and associated outcomes: A meta-analysis from Self-Determination theory. Unpublished manuscript.

Ketonen, E., Dietrich, J., Moeller, J., Salmela-Aro, K., \& Lonka, K. (2018). The role of daily autonomous and controlled educational goals in students' academic emotion states: An experience sampling method approach. Learning and Instruction, 53, $10-20$.

King, R. B., \& Datu, J. A. D. (2017). Materialism does not pay: Materialistic students have lower motivation, engagement, and achievement. Contemporary Educational Psychology, 49, 289- 301.

Kusurkar, R. A., Cate, T. J. T., Vos, C. M. P., Westers, P., \& Croiset, G. (2013). How motivation affects academic performance: A structural equation modelling analysis. Advances in Health Sciences Education, 18, 57- 69.

Landge, S., Sturges, D., Langdon, J., \& Orvis, J. N. (2019). A Path Analysis Study of Autonomous and Controlled Motivation and Final Course Grades. SoTL Commons Conference. 63. 
Leung, S. O., \&Xu, M. L. (2013).Single-Item Measures for Subjective Academic Performance, Self-Esteem, and Socioeconomic Status. Journal of Social Service Research, 1-10.

Manganelli, S., Cavicchiolo, E., Mallia, L., Biasi, V., Lucidi, F., \& Alivernini, F. (2019). The interplay between self-determined motivation, self-regulated cognitive strategies, and prior achievement in predicting academic performance. Educational Psychology, 39(4), 470-488.

Marfu'i, L. N. R., \& Sriyono, H. (2020, February). How is the Influence of Critical Thinking on Education Revolution Era 4.0?: A Pilot Study. In 3rd International Conference on Learning Innovation and Quality Education (ICLIQE 2019) (pp. 369-377). Atlantis Press.

Naz, S., Shah, S. A., \& Qayum, A. (2020). Gender Differences In Motivation And Academic Achievement: A Study Of the University Students of KP, Pakistan. Global Regional Review, 1, 67-75.

Orsini, C. A., Binnie, V. I., \& Jerez, O. M. (2019). Motivation as a Predictor of Dental Students' Affective and Behavioral Outcomes: Does the Quality of Motivation Matter?. Journal of dental education, 83(5), 521-529.

Orsini, C., Binnie, V., Wilson, S. \& Villegas, M. J. (2018). Learning climate and feedback as predictors of dental students' self-determinedmotivation: The mediating role of basic psychological needssatisfaction. European Journal of Dental Education, 22(2), 228-236.

Pintrich, P. R., Smith, D. A., Garcia, T., \& McKeachie, W. J. (1993). Reliability and predictive validity of the Motivated Strategies for Learning Questionnaire (MSLQ). Educational and psychological measurement, 53(3), 801-813.

Ranellucci, J., Hall, N., Muis, K., Lajoie, S., \& Robinson, K. (2017). Mastery, Maladaptive Learning Behaviour, and Academic Achievement: An Intervention Approach. Canadian Journal of Education/Revue canadienne de l'éducation, 40(4), 704738.

Ryan, R. M., and Deci, E. L. (2017). Self-determination Theory: Basic Psychological Needs in Motivation, Development, and Wellness. New York, NY: Guilford Press.

Sarkis, A. S., Hallit, S., Hajj, A., Kechichian, A., Sarkis, D. K., Sarkis, A., \& Ayoub, E. N. (2020). Lebanese students' motivation in medical school: does it change throughout the years? A cross-sectional study. BMC medical education, 20(1), $1-10$.

Siwek, Z., Oleszkowicz, A., \& Stowinska, A. (2017). Values Realized in Personal Strivings and Motivation, and Meaning in Life in Polish University Students. Journal of Happiness Studies, 18, 549-573.

Smith, E., \& White, P. (2015). What makes a successful undergraduate? The relationship between student characteristics, degree subject and academic success at university. British Educational Research Journal, 41(4), 686-708.

Soufi, S., Damirchi, E. S., Sedghi, N., \& Sabayan, B. (2014). Development of structural model for prediction of academic achievement by global self-esteem, academic self-concept, self-regulated learning strategies and autonomous academic motivation. Procedia - Social and Behavioral Sciences, 114, 26-35. 
Sutiani, A., Situmorang, M., \& Silalahi, A. (2021). Implementation of an Inquiry Learning Model with Science Literacy to Improve Student Critical Thinking Skills. International Journal of Instruction, 14(2), 117-138.

Triandis, H. C. (2018). Individualism and collectivism. NY, USA: Routledge.

Tsoi, S. L. T. A., de Boer, A., Croiset, G., Koster, A. S., van der Burgt, S., \& Kusurkar, R. A. (2018). How basic psychological needs and motivation affect vitality and lifelong learning adaptability of pharmacists: a structural equation model. Advances in Health Sciences Education, 23(3), 549-566.

Vallerand, R. J., Pelletier, L. G., Blais, M. R., Brière, N. M., Senecal, C., \& Vallières, É. F. (1993). On the assessment of intrinsic, extrinsic, and amotivation in education: Evidence on the concurrent and construct validity of the Academic Motivation Scale. Educational and psychological measurement, 53(1), 159-172.

Van Soom, C., \& Donche, V. (2014). Profiling first-year students in STEM programs based on autonomous motivation and academic self-concept and relationship with academic achievement. PloS one, 9(11), e112489.

Vansteenkiste, M., Zhou, M., Lens, W., \& Soenens, B. (2005). Experiences of autonomy and control among Chinese learners: Vitalizing or immobilizing? Journal of Educational Psychology, 97, 468-483.

Wormington, S. V., Corpus, J. H., \& Anderson, K. G. (2012).A person-centered investigation of academic motivation and its correlates in high school. Learning and Individual Differences, 22(4), 429-438.

York, T. T., Gibson, C., \& Rankin, S. (2015). Defining and measuring academic success. Practical Assessment, Research \& Evaluation, 20(5), 1-20. 